\title{
Nursing students' experiences of caring for dying patients and their families: a systematic review and meta-synthesis ${ }^{\dagger}$
}

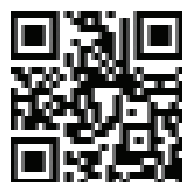

Original article

Yan Wang*

School of Health Science and Sports, Macao Polytechnic Institute, de Luís Gonzaga Gomes, Macao 999078, China

Received: 12 October 2018; Accepted: 5 February 2019; Published: 20 December 2019

Abstract: Objective: Nurses play important roles in caring for dying patients and their families. Difficulties students confronted when facing dying patients challenge the quality of nursing education. A better understanding of students' experiences would enhance teachers' ability in helping students. This study aims to describe available evidence about nursing students' experiences when caring for dying patients and their families.

Methods: A review of qualitative studies published between 2005 and 2017 was undertaken using the following databases: MEDLINE, CINAHL, ProQuest Central, ScienceDirect, and CNKI. The keywords included were nursing students, experience, care, end-of-life, and dying. Qualitative Assessment and Review Instrument was used to assess the quality of the studies by two independent reviewers. The data from the studies were analyzed by meta-synthesis.

Results: Eighteen English and two Chinese studies were selected in this review. Four themes were emerged: (1) Students with dying patients: students did not have enough ability in symptoms control, comfort supply, and therapeutic communication for dying patients. (2) Students with the patients' families: students advocated more caring for patients' families. (3) Students with the surroundings: professional medical staffs, especially the nursing preceptors, were key roles in constructing a supporting system for students. (4) Students with themselves: nursing students underwent various negative feelings and adopted both negative and positive strategies to cope with such feelings; students experienced professional and personal development during the caring for dying patients.

Conclusions: Nursing students' abilities in terminal symptom control, comfort supply, and therapeutic communication should be improved by more theoretic learning and simulation practice. The nursing preceptors were key roles in constructing a supporting system for students and helping them to control the negative emotions when facing dying patients.

Keywords: experiences $\bullet$ caring for dying patients $\bullet$ nursing student $\bullet$ qualitative studies $\bullet$ meta-synthesis

(c) Shanxi Medical Periodical Press.

${ }^{\dagger}$ This project was supported by the Macao Science and Technology Development Fund (No. FDCT 276/2017/P).

How to cite this article: Wang Y. Nursing students' experiences of caring for dying patients and their families: a systematic review and meta-synthesis. Front Nurs. 2019; 4: 261-272.

* Corresponding author.

E-mail: ywang@ipm.edu.mo (Y.Wang).

¿ Open Access. (๑) 2019 Yan Wang, published by Sciendo. (c) BY-NC-ND This work is licensed under the Creative Commons Attribution NonCommercial-NoDerivatives 4.0 License. 


\section{Introduction}

Life and death are permanent puzzles for human beings. Life and death educations since World War II have been carried out for years to educate medical and nursing students. Nurses spend more bedside time with patients than the other health professions and play an important role in caring for dying patients. The question for nursing educators is whether nursing education has equipped the students with enough ability in caring for dying patients and their families. Nursing students' experiences are a good answer to this question. Students' experiences would show educators a picture about what they encountered, how they felt, and how they handled when facing the dying patients and their families.

Nowadays, nursing researchers employed more and more qualitative methods to detect complex phenomena, which were presented in complex describing words. But conclusions of these qualitative research could scarcely be found. Sandalowski et al. ${ }^{1}$ claimed that researchers conducting qualitative studies did not accumulate knowledge gained from their studies. Qualitative data were hard to synthesize because of their complex nature. Meta-synthesis is a practical method to integrate the qualitative data. ${ }^{2}$

This systematic review of this study aims to describe available evidence about nursing students' experiences when caring for dying patients and their families.

\section{Methods}

\subsection{Types of participants}

The dying patient in this research refers to the patient who has been diagnosed with an illness in its final stage or as untreatable, or with a poor prognosis. The populations of including studies were nursing students who had the experiences of caring for dying patients and their families during their clinical rotation.

\subsection{Type of studies}

The methodology of including studies was qualitative research. Qualitative meta-synthesis includes the phenomenology, ethnographies, grounded theories, and other coherent descriptions or explanations of phenomena, events, or cases.

\subsection{Search strategy}

The studies published between 2005 and 2017 were retrieved from the following databases: MEDLINE, CINAHL, ProQuest Central, ScienceDirect, and CNKI.
The keywords included are nursing students, experience, care, end-of-life, and dying.

\subsection{Assessment of methodological quality}

Qualitative Assessment and Review Instrument (QARI), designed by the Joanna Briggs Institute, is used to facilitate critical appraisal, data extraction, and metaaggregation of the findings of qualitative studies. QARI includes the following 10 items: (1) there is a congruity between the stated philosophical perspective and the research methodology; (2) there is a congruity between the research methodology and the research question or objectives; (3) there is a congruity between the research methodology and the methods used to collect data; (4) there is a congruity between the research methodology and the representation of results; (5) there is a congruity between the research methodology and the interpretation of the results; (6) there is a statement locating the researcher culturally or theoretically; (7) the influence of the researcher on the research, and vice versa, is addressed; (8) participants, and their voices, are adequately represented; (9) the research is ethical according to current criteria or for recent studies, there is evidence of ethical approval by an appropriate body; and (10) conclusions are drawn in the research report do appear to flow from the analysis, or interpretation, of the data. The retrieved articles were assessed item by item and marked by yes, no, or unclear by two independent reviewers. The consensus on whether to exclude or to include the research was achieved through discussion between the two reviewers.

Initially, 154 articles related to this topic were found. After ruling out the quantitative research, simulation education research, and research on the experiences of nurses, and repeated articles, 33 articles were reviewed. After the quality evaluation by QARI, 18 English and 2 Chinese studies were selected in this review (Table 1).

\subsection{Data extraction and synthesis}

Data were extracted only from the articles that met the quality standards specified in Table 2.

The results of qualitative studies were analyzed by meta-synthesis. Qualitative meta-synthesis is a contemporary research approach used to conduct systematic reviews in social, behavioral, and health sciences. The collective findings from qualitative meta-synthesis on a specific phenomenon might yield greater insight than those derived from any single study. ${ }^{2}$ The principal reviewer developed an initial codebook and discussed it with the co-reviewer until a consensus on the codes meaning and coding process was achieved. Two coreviewers worked independently using the codebook. 


\begin{tabular}{|c|c|c|c|c|c|c|c|c|c|c|}
\hline \multirow[t]{2}{*}{ Research } & \multicolumn{10}{|c|}{ QARI items } \\
\hline & $(1)$ & $(2)$ & $(3)$ & $(4)$ & $(5)$ & $(6)$ & $(7)$ & $(8)$ & $(9)$ & $(10)$ \\
\hline Kiger $^{3}$ & $U$ & $Y$ & $Y$ & $Y$ & $Y$ & $U$ & $Y$ & $Y$ & $Y$ & $Y$ \\
\hline Beck $^{4}$ & Y & Y & Y & Y & Y & $U$ & $\cup$ & Y & Y & Y \\
\hline Cooper and Barnett ${ }^{5}$ & Y & Y & Y & Y & Y & $U$ & Y & Y & Y & Y \\
\hline Van Rooyen et al. ${ }^{6}$ & Y & Y & Y & Y & Y & Y & Y & Y & Y & Y \\
\hline Allchin ${ }^{7}$ & Y & Y & Y & Y & Y & $U$ & $U$ & Y & Y & Y \\
\hline Terry and Carroll8 & Y & Y & Y & Y & Y & $U$ & $U$ & Y & Y & Y \\
\hline Wang et al. ${ }^{9}$ & Y & Y & Y & Y & $Y$ & $U$ & $\cup$ & Y & Y & Y \\
\hline Sadala and da Silva ${ }^{10}$ & Y & Y & Y & Y & Y & $U$ & $\cup$ & Y & Y & Y \\
\hline Huang et al. ${ }^{11}$ & Y & Y & Y & Y & Y & $U$ & Y & Y & Y & Y \\
\hline Sanford et al. ${ }^{12}$ & Y & Y & Y & Y & Y & $U$ & $U$ & Y & Y & Y \\
\hline Parry ${ }^{13}$ & Y & Y & Y & Y & Y & $U$ & $U$ & Y & Y & Y \\
\hline Lu and Shi14 & Y & Y & Y & Y & Y & $U$ & $U$ & Y & Y & Y \\
\hline Charalambous and Kaite ${ }^{15}$ & Y & Y & Y & Y & Y & $U$ & $U$ & Y & Y & Y \\
\hline Muñoz-Pino ${ }^{16}$ & Y & Y & Y & Y & Y & $U$ & $\cup$ & Y & Y & Y \\
\hline Adesina et al. ${ }^{17}$ & Y & Y & Y & Y & Y & $U$ & $U$ & Y & Y & Y \\
\hline Kristina et al. ${ }^{18}$ & Y & Y & Y & Y & Y & $U$ & $U$ & Y & Y & Y \\
\hline Sampaio et al. ${ }^{19}$ & Y & Y & Y & Y & Y & $U$ & $U$ & Y & Y & Y \\
\hline Colley ${ }^{20}$ & $U$ & Y & Y & Y & Y & $U$ & $U$ & Y & Y & Y \\
\hline Österlind et al. ${ }^{21}$ & $Y$ & Y & Y & Y & $Y$ & $U$ & $U$ & Y & Y & Y \\
\hline Garrino et al. ${ }^{22}$ & Y & Y & Y & Y & Y & $U$ & $U$ & $Y$ & $Y$ & $Y$ \\
\hline
\end{tabular}

Note: Y: yes; U: unclear.

Table 1. Quality assessment of the included articles.

They individually and repeatedly read all included articles to become immersed in the data. The data were categorized based on the emerging meanings. Checking and rechecking of the coding were used to enhance confirmability. The modifications, deletions, and additions were carried out until the consistency in coding was achieved. Finally, the synthesized data were reviewed again among the two reviewers to validate interpretations and conclusions and reduce the possibility of the reviewer's preconceptions affecting the ways data were perceived and interpreted. An example of the meta-synthesis process is presented in Table 3.

\section{Results}

Eighteen English and two Chinese articles were included in this meta-synthesis. Four themes and nine subthemes were identified in the meta-synthesis (Table 4).

\subsection{Students with the dying patient}

Although as some students mentioned, theoretic learning and practicing in the nursing laboratory were beneficial, the most important and efficient way to learn to care for dying patients was practicing in clinical situations. All students of the included research gained the experiences of caring for dying patients during their clinical rotation.

\subsubsection{Inadequacy in symptom control and comfort supply}

When facing patients without urgent physical symptoms, for example, the patients who came to the hospital for regular chemotherapy or wound dressing, students shared more positive experiences. ${ }^{12}$ Improvement of the physical symptoms sometimes made students forget about the imminent death.

It was sad to see the physical deterioration of patients. Students complained that they did not be trained enough to handle the physical symptoms of dying in nursing curriculum. , $^{9} 13-15,19$ Students' inexperience might be magnified by the nervous patients and families, resulting in their anxiety even guilty. 7,10 The most common and unendurable symptom mentioned by students was the pain. ${ }^{4,10,12,16,18,19}$ Students had a strong desire to stop the pain, always doubting that the physician did not give enough analgesics to permit a more comfortable death to the patient. ${ }^{4,5}$ Students felt extremely suffering when watching the dying patient in 


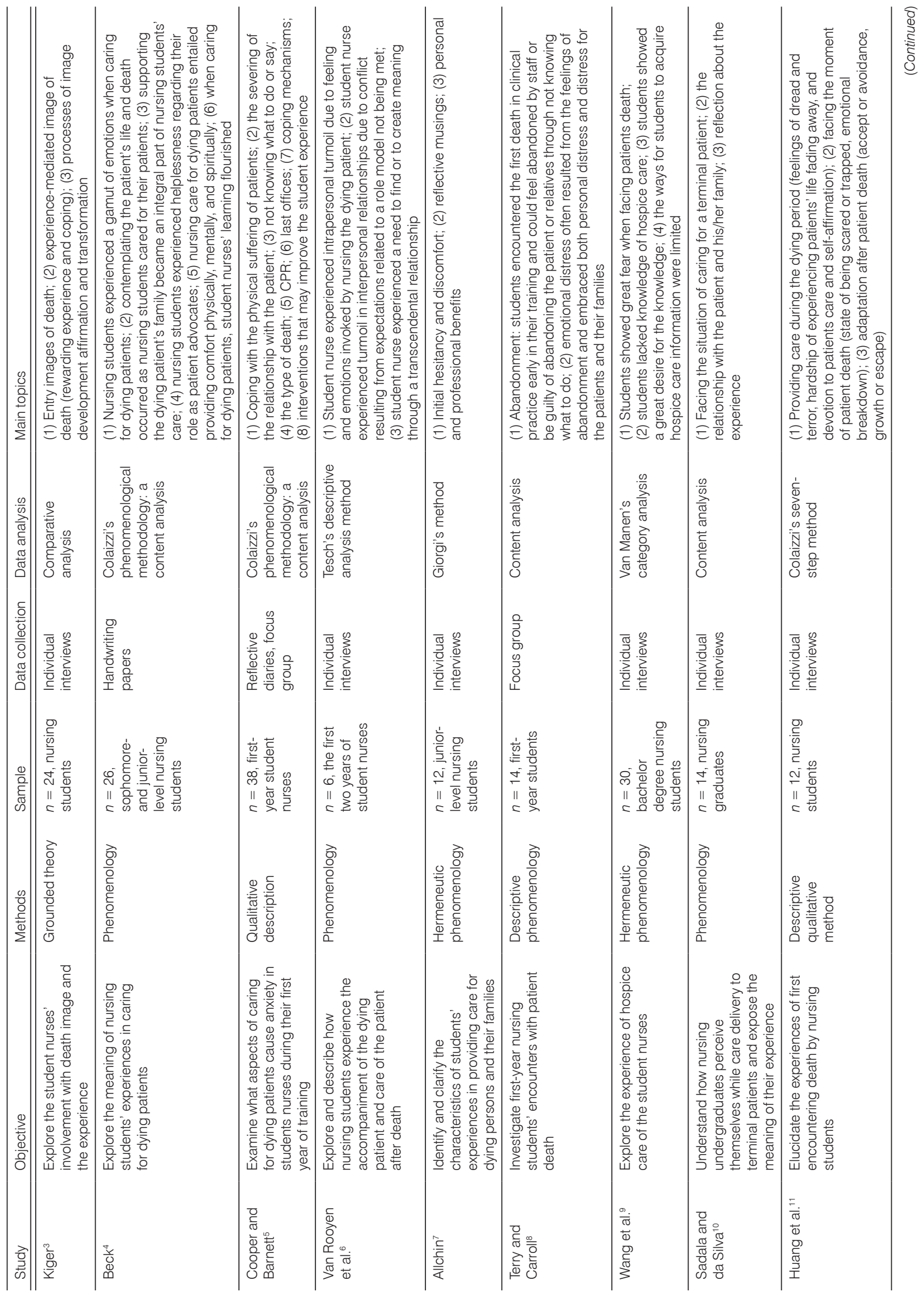




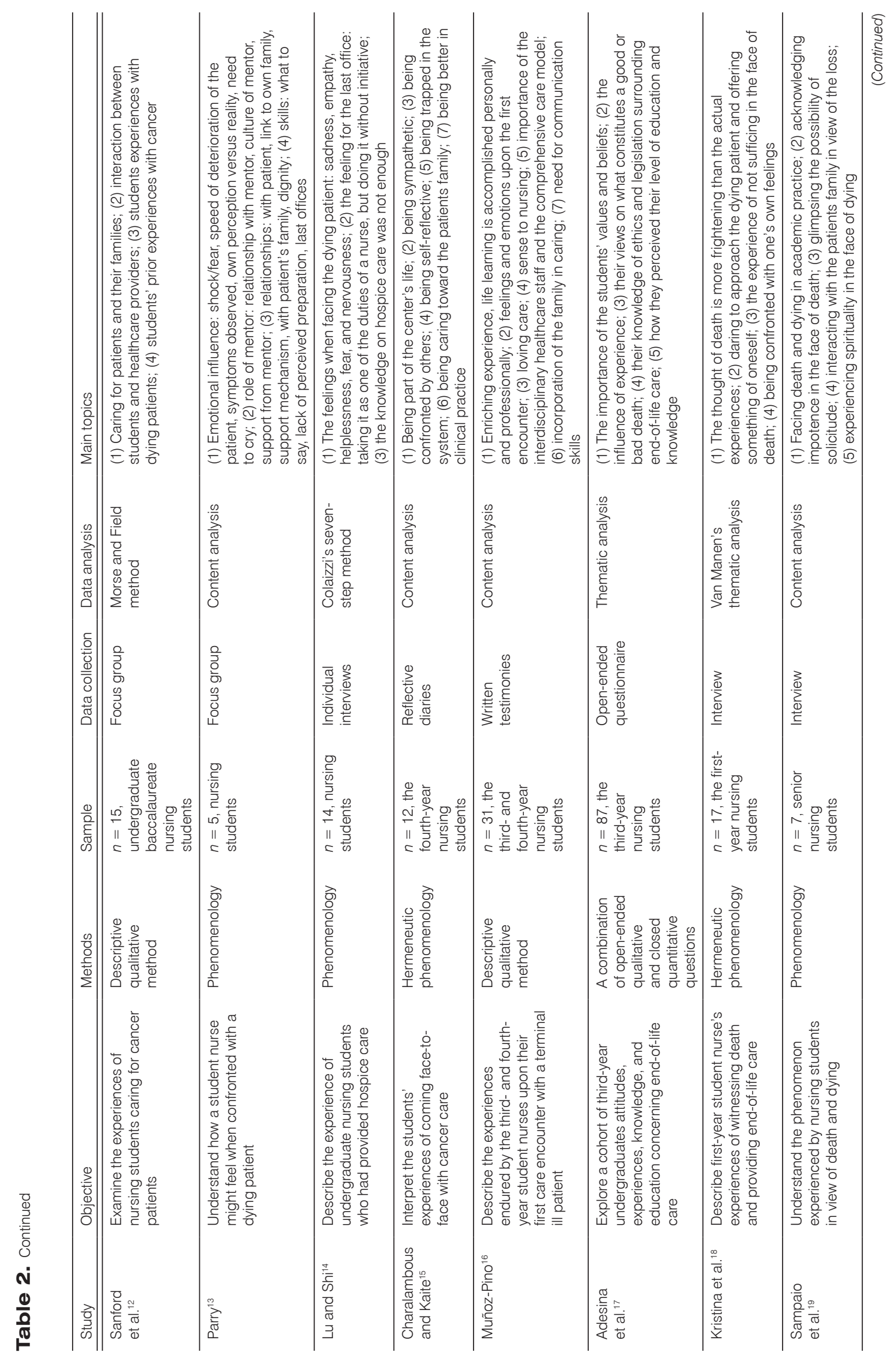




\begin{tabular}{lll}
\hline Codes & Sub-theme & Theme \\
\hline \hline Fear/shock & $\begin{array}{l}\text { Emotional } \\
\text { challenges }\end{array}$ & $\begin{array}{l}\text { Students with } \\
\text { themselves }\end{array}$ \\
Anxious & & \\
Being on a roller coaster & \\
Satisfactory & \\
Exhausting & \\
Shatter in pieces & \\
Awkward & \\
Impotent & \\
Trapper & \\
Helpless & \\
Angry & \\
Self-doubt & \\
Guilty & \\
Mediated & \\
Detachment & \\
Switch off & \\
Reject & \\
Quit & \\
Cry & \\
Talk and share & \\
\hline
\end{tabular}

Table 3. The example of meta-synthesis for one theme of nursing students for caring for dying patients and their families.

\begin{tabular}{ll}
\hline Theme & Sub-theme \\
\hline \hline Students with dying patients & $\begin{array}{l}\text { Inadequacy in symptom control } \\
\text { and comfort supply } \\
\text { Inability in therapeutic } \\
\text { communication } \\
\text { Last offices }\end{array}$ \\
\hline Students with patients' families & More concern for families \\
\hline Students with surroundings & Nursing preceptors' supporting \\
& Other medical staff's effects \\
& Over-workload in the clinic \\
\hline Students with themselves & Emotional challenges and coping \\
& Personal and professional growth \\
\hline
\end{tabular}

Table 4. Themes and sub-themes on the experiences.

pain and not knowing what to do. Students sometimes suspected the meaning of their work when physical symptoms could not be relieved by the nursing skills. Limited methods, such as body cleaning and massage, were mentioned by the students to improve the comfort for patients..$^{411,18}$

\subsubsection{Inability in therapeutic communications}

Besides the physical suffering, the student witnessed the mental suffering of the patients. Comparing with 
providing physical care, students showed less confidence in providing emotional care for dying patients. Emotional care can be practiced through therapeutic communications. Students said that although they had learned and practiced the communication skills in the school, they could not handle the situations when facing a dying patient. ${ }^{3,4,7,10,13,16,20}$ They did not know how to answer the patient's question such as how long I could live. They did not know how to explain the poor prognosis of the disease. Students complained that when left alone with the dying patient they even did not know what to say. They worried about becoming an intruder to discuss with the patient about very personal problems, such as death.

Some students mentioned their personal history of taking care of their dying relatives or friends made them more familiar with the situation and having a better understanding of what the patient was going through. Students found praying with patients sharing the same religion could relieve the suffering. Sometimes even sitting quietly with the patient might be a special communication method to comfort the dying patient. ${ }^{4,11,18}$

\subsubsection{Last offices}

The last offices can be regarded as the last step to finish nursing for dying patients. For most students, last offices were acceptable and they could finish with prudence and respect. They said that the last office was compulsory work for nursing, so they must finish it. But some procedures, such as packing the orifices, pulling out the catheters, and removing personal belongings, made them show less initiative in last offices. . $^{53,14}$

\subsection{Students with the dying patient's families}

Students identified their experiences with supportive families as meaningful interaction and advocated to integrate caring the dying patient's families into the nurses' duty. 4,11,16,19,21 Students witnessed families' sufferings, such as pretending happy in front of the patient while hiding the cruel truth and sadness inside. They indicated the abandonment of the relatives regularly occurred. ${ }^{8}$ When providing urgent life-saving treatment to the patient, families were always left alone in the office. More caring should also be paid to the suffering families. After the patient's death, more nurse's time and attention should be given to the families. Although not easy, especially with families in an intensive care unit or with pediatric families, many students emphasized that they harvested lots of appreciations during the caring process.

\subsection{Students with the surroundings}

Caring for the dying is interdisciplinary work. Students sometimes experienced good relationships with clinical staff, regarding the clinic as a "big family". ${ }^{15}$ They appreciated the knowledge and professional behaviors of the medical staff, regarding them as career role models. They also thought that the comforts and encouragement from the preceptors could relieve their distress when facing dying patients. ${ }^{13,22}$ Because of the heavy workload of nurses, many students felt abandoned because they did not receive enough guidance and support from the preceptors. ${ }^{6,8,12,15}$

The interactions with the physicians were also very important parts of students' experiences. Some students reported that they were impressed by the physicians' professional behavior, claiming learned lots of knowledge from physicians. And also, physicians' patience and caring for the dying patients touched students. ${ }^{12}$

Students thought that caring for dying patients was a good opportunity for them to practice what they had learned, but the clinics sometimes underestimated their ability and deprived them of acting upon such situations. Some students regarded it as a prejudice. ${ }^{6,19}$ Some students reflected the predominant mode of health care, which privileged technical-scientific care, ${ }^{8}$ setting aside the psychosocial needs of the person. They said that caring for the mental and spiritual suffering was always neglected. They found some unreasonable arrangements in the hospital, for example, the stiff visiting time, lack of social workers, and too-busy nurses. Students said inexperienced staff or shortage of nurses would finally result in decreased quality of care for dying. $8,12,18$ They reported that some nurses treated the dying without enough respect, for example, not ensuring privacy.

\subsection{Students with themselves}

\subsubsection{Emotional challenges and coping}

When caring for dying, students experienced a bundle of negative emotions, such as fear, anxiety, impotence, and helplessness. Most students mentioned the fear when facing the dying patients, especially in the first professional encounter. ${ }^{5,8,11}$ Some students even used the word "shock" to describe. ${ }^{5}$ A few students mentioned that the death image could be mediated by the true experiences of caring the dying patients, and they found that the reality might have been less dramatic than their original images. ${ }^{3,6,18}$ They were anxious when providing nursing skills with the dying patient. Anxiety originated from the in-confidence and inexperience. 
Students had dramatic emotional fluctuations, feeling happy and satisfactory when nursing skills succeeded whereas feeling frustrated and useless when nursing skills failed. ${ }^{19} \mathrm{~A}$ student called these fluctuations as "being on a roller coaster". ${ }^{15}$ When there was no hope for recovery, taking care of the dying patients became extremely exhausting. ${ }^{10}$ Students said that they felt shattered in pieces. ${ }^{15}$

Awkwardness came from the idea that death discussion about death was such a private thing and should not be carried out between the dying patients with the "stranger" nurse. They felt trapped, helpless even angry with themselves because they did not know what to say, especially when left alone with the patients. . $^{4,5,7,8,11}$ Students felt impotent when they saw the physical deterioration of the patients. Feeling guilty was common; a minor mistake might induce students' severe self-doubt, suspecting that the patients' death might be caused by them. ${ }^{6,10}$

The anxiety would reach the maximum during the cardiopulmonary resuscitation (CPR) because students understood that their minor mistake could make a difference in whether the patient lived or died. ${ }^{5}$ The last offices were also an anxiety-provoking procedure. The type of death could affect students' feelings. They found that sudden or young death was more distressing than the expected or old death. ${ }^{5,12}$ Some students expressed frustration because patients' in-avoidance death reminded them the limitation of medical science. ${ }^{6}$ A few students mentioned that they did not feel hard to handle their emotions, and they could leave it behind quite easily. ${ }^{3}$

Students showed positive and negative coping strategies with negative feelings. Students found more involvement with the dying patient and more sadness when the patient died. ${ }^{5,13,22}$ They tried to keep an emotional distance from the patients, which was called the detachment. 4,6,15,21,22 They did not look at the patient's eyes, did not discuss the death with the patients, and finished the nursing skills just technically. Some students tried to switch off all the feeling receptors, pretending felt nothing. ${ }^{5}$ Students said such suppression and avoidance might have some effects to hold their sadness at the beginning, which could not last for a long time.

Emotional breakdown broke out sooner or later, which is triggered by some special events, such as the great pain of the patient or emotional outbursts of the families. Such traumatic experiences would result in students' rejection of dying-caring duty, even quit from a nursing career. ${ }^{3}$ Some students found that crying or praying to a higher being/God was a useful way to relieve their sadness. ${ }^{6} \mathrm{~A}$ few students referred to one useful method of coping was to talk and share with the other students who had the same experiences. ${ }^{5,6}$

\subsubsection{Professional and personal development}

Caring for the dying benefited students both in dealing with such clinical situation and in personal development. $7,11,16,17$ By caring for the dying and witnessing the death, abstract death became more real. Students discarded the unrealistic expectations of medicine and nursing. Saving life was the most important objective of nursing, but it is not the only objective. Nurses could help patients even without the expectation of their improvement or survive.

Some students thought that practical experiences could eliminate their fearful fantasies to death. The past life experience gave them an uncompleted picture of death, and the theoretical learning in school might emphasize the rational and negative aspects of death. The clinical experiences mediated their images on death. ${ }^{3,16,18}$ They found that dying and death were less dramatic than they imagined. By caring for the dying physically, mentally, and spiritually, students improved their professional ability. They were very satisfied when ensuring the privacy for the patients, when supplying more information on the diseases, and when sharing the feelings on death. They cared for people every day and also received thanks every day.

Some believed that they could supply better nursing care for the dying when encountered such situations again in the future. ${ }^{10}$ They said that nursing was a very important job because nurses not only helped people's living but also helped people's dying. Some students accredited caring for the dying "the good" nature of the nursing career; they thought that it was the most poignant form of helping people. ${ }^{3}$ Students appreciated the trust given by the dying patients, and they also commented that the interaction with patients' families was rewarding. The good relationship built in such a tough situation strengthen themselves in the meaning of their lives and the nursing profession.

Students reported that sometimes they could not help contemplating the life of the patient, imagining what kind of life he had led. It was a positive reflection which showed that student treated the patients as a "real" human being, owing background, stories, and feelings. ${ }^{4}$ Among the nursing students, the acceptance of Do Not Resuscitation (DNR) was not very high. Generally, students equated DNR issues with "giving up", which meant that no further nursing would be applied to the patient. They thought that the behavior of giving up life was inhumanity. ${ }^{5}$ 
Students' reflection on life and death helped them in personal development. Taking care of the dying generated them to reflect on their death. ${ }^{12}$ They realized the fragility of life and cherished life more than ever before, beginning to considering the meaning of lives. ${ }^{19}$ They spent more time with their families and planned their lives more prudently. ${ }^{11}$ Because of the inevitability of death, students emphasized the importance of achieving a "good death". Deaths occurring, not in a sudden, at the old age, during sleep, with dignity, with finished last wishes, surrounded by families, and without pain, were described by students as good deaths. ${ }^{17}$

\section{Discussion}

Caring for the dying in physical, mental, and spiritual aspects simultaneously is difficult for inexperienced student nurses. In the past, we exaggerated students' fear of patients' death. What we could find in this metasynthesis shows that students' negative emotions came more from the inability to comfort the patients than from the fear of their death. Students would not think about their death whenever they cared the dying. They were far more acceptable for death than we imagined. We have not trained students enough to comfort the terminal symptoms. For example, they expressed anxiety about the pain, but they did not share any useful methods to relieve the pain, putting all the hopes on analgesics. Students lost confidence and creativity without enough preparation. There were many methods could relieve the terminal pain, and students showed their limitations on the palliative care knowledge and skill. This research found rarely that students shared their experiences on other terminal symptoms, such as respiratory distress, fumigating wound, oral ulcer, and constipation.

Such detailed problems constructed the daily life of dying patients. Since the death could not be avoided, nurses should dedicate to improve the quality of life of the patients by solving the symptoms. Students' neglect of other terminal symptoms indicated that they did not have the whole picture of dying patients, for their focus was attracted mostly by the most extraordinary symptom.

Students thought that their communication skills were not enough when facing the dying patients. Students just handled such situations by their intuition. With some incorrect ideas, such as nurses were invaders in death discussion, expressing that no emotion was professional behavior before the dying patients, students found it hard to use the communication skills learned in the classroom. The nursing curriculum has merged some communication skills into the program, but it is not enough.
Although as inexperience students, also as relatively objective observers, they had their views on the clinical circumstances. They were impressed by the professional behaviors of the physicians and nurses, gaining support from them. They have noticed that the shortage of nurses would compromise the quality of care delivering to the dying. Students wanted the clinical tutor to give them more trust, supplying more chances for them in caring for the dying patients.

These negative moods of students had shown devastating power. There was no evidence to show that students had been trained specially to handle the negative moods during the care of dying patients. And also students did not get enough guidance to cope with such situations.

Professional development not only means skilled nursing techniques but also indicates strong and rational minds. Students emphasized more on emotional development than on skill development. Students said that they witnessed the power of care, regarding the caring for dying as an honor for nurses. It was a great professional improvement when students could integrate care into their careers automatically. They paid a high value on relationship constructions between them and the dying patients. Tough feelings and experiences resulted in positive professional development, which could be credited to students' kindness and dedication to nursing.

The process facing someone else's death was a touching process, which could provoke deep meditation on life and death. They began to review their lives, trying to figure out the most important things in lives. Also, students began to think about their death, doing some preparation for it.

During the years of nursing education, students learned that nurses could do many things, which resulted in a hallucination that doctors and nurses could save the lives of dying patients at last by keeping trying. By caring for dying, students confront the limitation of medical sciences. Since human beings could not avoid death, students tried to define a more "acceptable" death, named "good death". This behavior had deduced the idea that there was something we could do to make the death less suffering. That is the way out for the avoidance of death.

\section{Conclusions}

The systematic review provides a more deeper and more comprehensive understanding of students' experiences in caring for the dying. It shows that students did not have enough ability in caring for dying patients, lacking in the theory and skill for terminal symptoms. Also, students found frustrations in communication with the 
patients and their families. All these difficulties arouse students' negative emotions, and they did not show suitable and enough coping strategies. Clinical preceptors showed a professional role model for students, but sometimes preceptors did not give students enough supporting for caring the dying because of overloaded working. Students got improvement in the nursing profession by witnessing the power of care and constructing an objective view of medical science. Students gained self-development by reflection on the question of life and death. They prepared to lead a more positive and prudent life.

\section{Recommendations}

The best and practical way to reduce students' negative feelings when facing the dying patients is to improve nursing students' ability in terminal symptom caring. Nursing educators should merge the care for dying patients into the nursing curriculum. Terminal care, as an independent subject, can be arranged in the third or fourth year in the bachelor curriculum. After finishing the medical-surgical nursing, pediatric nursing, and gynecologic nursing, students will be easier to understand the mechanism of terminal symptoms. The theories and skills of terminal symptoms' control and comfort supply should be introduced. Before the clinical rotation, simulation education in the nursing laboratory supplies students a safe and true situation to practice, which permits students putting their knowledge into practice. For example, we can set a scenario, using a medical educational robot to simulate terminal symptoms, having students to evaluate and care for the dying, and setting the laboratory as a hospice ward. Also, we can add the family members in the scenario who were acting by students. Role-playing can let students practice communication skills and improve students' understanding of dying patients' families.

\section{References}

1. Sandelowski M, Docherty S, Emden C. Qualitative meta-synthesis: issues and techniques. Res Nurs Health. 1997;20:364-371.

2. Sandelowski M, Barroso J. Handbook for Synthesizing Qualitative Research. New York: Springer Publishing Company; 2006.

3. Kiger AM. Student nurses' involvement with death: the image and the experience. $J A d v$ Nurs.1994;20:679-686.

4. Beck CT. Nursing students' experiences caring for dying patients. J Nurs Educ. 1997;36:408-415.
When clinical rotation begins, ensure every medical staff member constructs a supporting atmosphere in the clinic. More trust should be given to students to carry out caring for dying patients under the supervision of the preceptors. Having learned and been trained the terminal care in school, students will have more confidence in facing the dying. We should allow students to attend pre- and post-briefing about the dying or death case, and including the expert clinicians can be an efficient way to transfer the knowledge and share experiences with students.

We should train our clinical preceptor to be more sensitive to students' negative moods caused by caring for the dying. Organizing students with the same experiences to discuss will be helpful to release their anxiety. We also can invite expertise nurses to share their experiences on negative emotion control.

This research also suggests that our future education should keep on reminding students that there was something beyond human reach, and we should not feel guilty when we had tried our best. If students know the limitation of medical sciences and try all that we could, death might be more acceptable.

\section{Acknowledgment}

We extend our great thanks to Dr. Haobin Yuan, Macao Polytechnic Institute, in helping for data reviews and analysis.

\section{Ethics approval}

This study was approved by the ethics committee of Macao Science and Technology Development Fund (Program: FDCT 276/2017/P).

\section{Conflicts of interest}

There are no conflicts of interest.
5. Cooper J, Barnett M. Aspects of caring for dying patients which cause anxiety to first-year student nurses. Int J Palliat Nurs. 2005;11:423-430.

6. Van Rooyen D, Laing R, Kotzé WJ. Accompaniment needs of nursing students related to the dying patient. Curationis. 2005;28:31-39.

7. Allchin L. Caring for the dying nursing student perspective. J Hospice Palliative Nurs. 2006;8:112-117.

8. Terry LM, Carroll J. Dealing with death: first encounters for first-year nursing students. $\mathrm{Br} J$ Nurs. 2008;17:760-765. 
9. Wang YL, Yang Y, Wen HY. Qualitative study on the true experience of hospice care in undergraduate nursing students during their internship. Nurs $J$ Chin PLA. 2009;26:1-6 (in Chinese).

10. Sadala ML, da Silva FM. Taking care of terminal patients: nursing students' perspective. Rev Esc Enferm USP. 2009;43:287-294.

11. Huang $X Y$, Chang JY, Sun FK, Ma WF. Nursing students' experiences of their first encounter with death during clinical practice in Taiwan. J Clin Nurs. 2010;19:2280-2290 (in Chinese).

12. Sanford J, Townsend-Rocchiccioli J, Quiett K, Trimm D. "I see my mother's face": student nurse experiences caring for cancer patients. Eur J Oncol Nurs. 2011;15:46-52.

13. Parry M. Student nurses' experience of their first death in clinical practice. Int $J$ Palliat Nurs. 2011;17:446-451.

14. Lu J, Shi TY. Experience of undergraduate nursing students providing hospice care. Med Philos. 2013;483:72-74 (in Chinese).

15. Charalambous $A$, Kaite $C$. Undergraduate nursing students caring for cancer patients: hermeneutic phenomenological insights of their experiences. BMC Health Serv Res. 2013;13:63.
16. Muñoz-Pino IP. Experience of nursing students upon their first care encounter with terminally ill patients. Invest Educ Enferm. 2014;32:87-96.

17. Adesina O, DeBellis A, Zannettino L. Third-year Australian nursing students' attitudes, experiences, knowledge, and education concerning end-of-life care. Int J Palliat Nurs. 2014;20:395-401.

18. Kristina EK, Westin L, Prahl C, et al. Death and caring for dying patients: exploring first-year nursing students' descriptive experiences. Int J Palliat Nurs. 2014;20:509-515.

19. Sampaio AV, Comassetto I, Faro AC, Dos Santos RM, Monteiro FS. The experience of nursing students facing death and dying. Invest Educ Enferm. 2015;33:305-314.

20. Colley SL. Senior nursing students' perceptions of caring for patients at the end of life. J Nurs Educ. 2016;55:279-283.

21. Österlind J, Prahl C, Westin L, et al. Nursing students' perceptions of caring for dying people, after one year in nursing school. Nurse Educ Today. 2016;41:12-16.

22. Garrino L, Contratto C, Massariello P, Dimonte V. Caring for dying patient and their families: the lived experiences of nursing students in Italy. $J$ Palliat Care. 2017;32:127-133. 